

\section{Opportunities for Voluntary Land \\ Consolidation in Ethiopia: \\ Farmers' Perspectives}

May 2019

Written by

Girum Getachew Alemu

Ezana Amdework Atsbeha

Larissa Stiem-Bhatia

Jes Weigelt

Acknowledgements

We wish to express our gratitude to our partner, GIZ Ethiopia/ISFM project, for their keen interest in the topic and for their continuous support throughout the research process.

We would like to express our gratitude to the farmers at the two study sites who participated in the research process and openly shared their views on this important and sensitive topic. Special thanks go to Mr. Biazen Abetew, who skilfully organised and supported the community consultation meetings.

The collaboration with CIAT Ethiopia was instrumental in undertaking the first national consultation workshop. CIAT Ethiopia also facilitated the collection of household survey data. Contact

Girum.alemu@tmg-thinktank.com

larissa.stiem-bhatia@tmg-thinktank.com
As part of the special initiative One World No Hunger, financed by the German Federal Ministry for Economic Cooperation and Development (BMZ), TMG Research gGmbH has provided research support to GIZ Ethiopia's Integrated Soil Fertility Management (ISFM) project in the highlands of the Amhara National Regional State. The TMG research project focusses on socio-economic, cultural and political-institutional factors that constrain farmers' uptake of Sustainable Land Management (SLM) practices. Exploring the potential of voluntary land consolidation as an instrument to tackle one important SLM adoption challenge - land fragmentation - has been at the core of TMG's work on this project

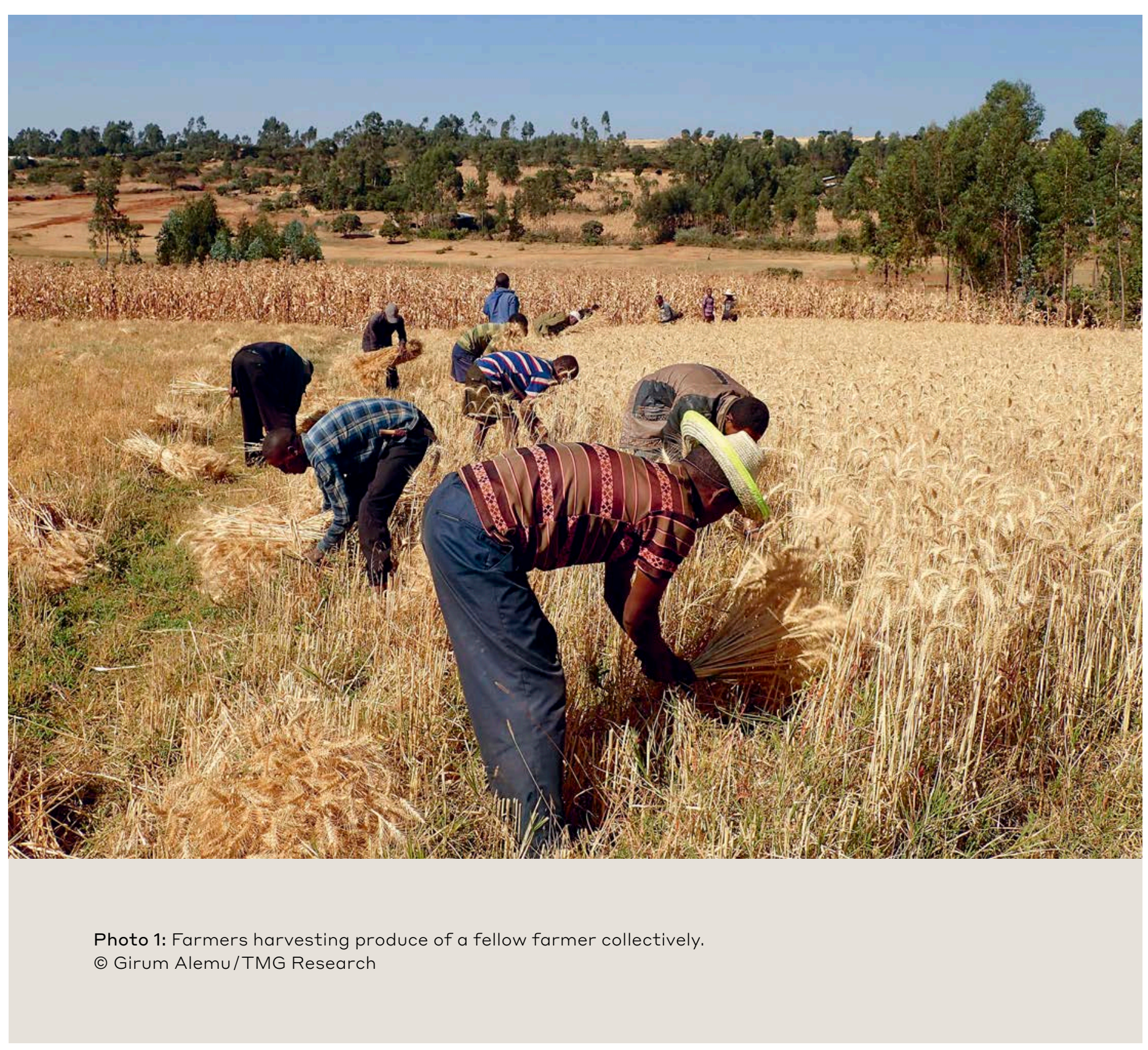


Table of contents

$$
\begin{aligned}
& \text { List of Figures } \\
& \text { List of Maps } \\
& \text { List of Photos } \\
& \text { List of Tables } \\
& \text { List of Acronyms }
\end{aligned}
$$

Key Messages

\section{Background}

Land consolidation in the Ethiopian context

Enabling policy environments for land consolidation

Methodology

The fragmentation of agricultural land and its challenges from farmers' perspectives

\section{Potential of voluntary land consolidation}

Way forward: Continued consultations and stakeholder engagement

5

\section{List of Figures}

Figure 1: Number of plots managed by respondents in Woreielu and Gozamen woredas

Figure 2: Adverse effects of land fragmentation by woreda

Figure 3: Perceived benefits of land consolidation

Figure 4: Circumstances under which farmers would prefer consolidation

Figure 5: Farmers' preferred locations for land consolidation

Figure 6: Reasons given by farmers for participating in plot exchange

List of Maps

Map 1: Map of the study region and woredas

List of Photos

Photo 1: Farmers harvesting produce of a fellow farmer collectively

Photo 2: Wheat harvest on fragmented farmlands.

Photo 3: Farmers operate on discontinuous farm plots not amenable to small mechanisation

18

21

\section{List of Tables}

Table 1: Number of parcels and distance

from homestead of selected landholders

References 


\section{Key messages}

1 Little has been done to address the problem of land fragmentation in Ethiopia, despite its multifaceted effects on agriculture.

2 Governmental and other stakeholders show interest in pursuing voluntary land consolidation (VLC) and in devising appropriate legal and policy frameworks.

3 Farmers at the case study site acknowledge the potential economic and social benefits of VLC if carried out in a participatory and inclusive manner with due consideration of land productivity factors.

Agricultural Transformation Agency Agricultural Commercialisation Cluste German Federal Ministry

for Economic Cooperation and Development International Centre for Tropical Agriculture Central Statistical Authority Development Agent

Enviopian Economic Association
Environmental Protection, Land Use and Administration Agency Federal Democratic Republic of Ethiopia

4 Further research covering additional kebeles is necessary to gather farmers' views and identify multiple potential scenarios for the implementation of VLC.

5 Participatory research with affected farmers combined with land policy research can stimulate policy dialogue and refine the federal and regional land regulations pertinent to VLC. 


\section{Background}

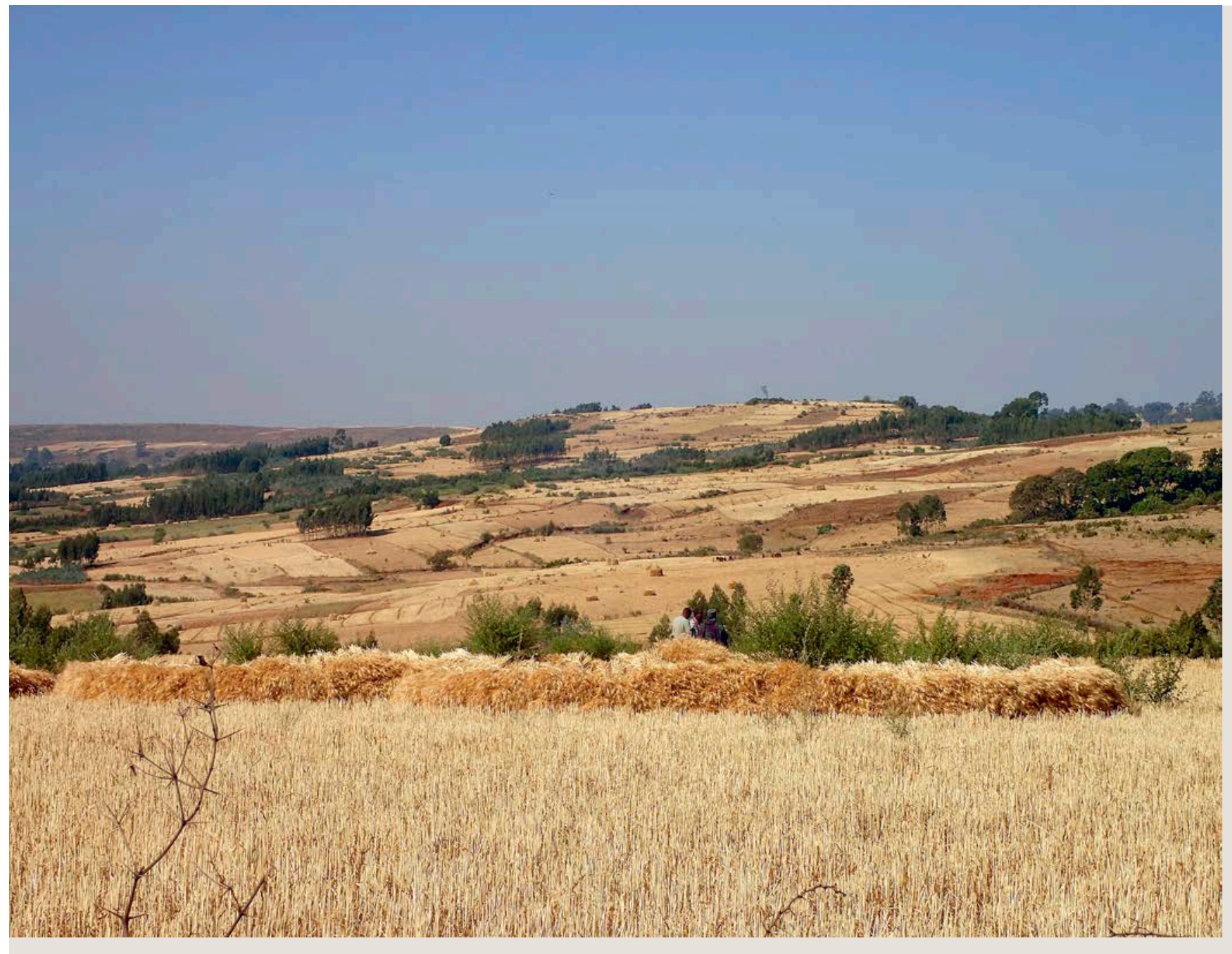

Photo 2: Wheat harvest on fragmented farmlands. (6) Girum Alemu/ TMG Research
Smallholder agriculture accounts for 85 per cent of Ethiopia's total agricultural output (Fantu et al 2015), and 60 per cent of farming households operate on less than one hectare of land (CSA 2015). Due to the low availability of farming land per capita and use of rudimentary farming methods, smallholder agriculture has failed to meet these farmers' subsistence needs (EEA 2002).

Many of these farms are split into numerous spatially dispersed parcels, exemplifying the phenomenon of land fragmentation in rural Ethiopia. Land fragmentation tion in rurat a thion refers to a situation where "... the cultivators' land is distributed among many
parcels or fragments, often of very small size...) (Daniel et al 2015). Analysts distinguish between four types of land fragmentation - of land ownership, of land use, within a farm (internal fragmentation), and with separation of ownership and use (Demetriou, 2014).

According to a study conducted in two widely differing farming communities in north-west Ethiopia, farmers may cultivate up to 14 scattered plots (Teshome 2009: 14) Nearly half of these (Tleshome 2009: 14). Nearly half of these plots were less than 0.2 hectares in area.
Ethiopia's agricultural policy makers therefore face the task of organizing a socially inclusive and sustainable rural transformation. Reorganizing land holdings that are predominantly characterised by small and fragmented holdings is one important aspect of this transformation.

This working paper discusses the opportunities for voluntary land consolidation in Ethiopia, based on qualitative consultations with farmers as well as on household survey data collected in two selected woredas 1 of Amhara region, Gozamen and Woren Woreitu Section II highlights the broader context of land consolidation in Ethiopia, and is followed by an overview of land policies pertaining to VLC with special focus on Amhara National Regional State (ANRS). Section four briefly outlines the methods used to conduct the research. Sections five and six present farmers views on the challenges of land fragmentation as well as the prospects for land tation as well as the prospects for land consolidation. The final section suggests a way to implement VLC based on the principles of voluntariness and inclusivity.

1 Woredas are the third-level administrative divisions in Ethiopia. Woredas are further divided into kebeles or neighbourhood associations, which represent thes 


\section{Land consolidation in the Ethiopian context}

For decades the Ethiopian government has considered smallholder agriculture as a key factor in its quest for rural development. To this end, especially over the last two decades, the government has put in place policy measures and undertaken action to enhance farm productivity, improve access to market and strengthen tenure security.

Fragmented landholdings, often ill-suited for farming, are not conducive to developing the economies of scale that are central to agricultural transformation. Despite the critical challenge of land fragmentation for agricultural development, this topic has received relatively little attention. The few available studies in the area of land governance focus on land tenure, land certification and other related issues but largely ignore land fragmentation (Rahameto 1994, Shimelles, Islam, and Parviainen, 2009, Enyew, et al., 2014).

Land fragmentation is also not substantially dealt with in terms of policy. So far, no nation-wide programme has addressed the issue of land fragmentation, which affects over 13 million farming households. However, over the last two decades, several isolated projects, such as the Agricultural Commercialization Cluster (ACC), have consolidated adjacent lands (ATA 2017).

Land consolidation in developing countries such as Ethiopia is pivotal to rural development and transformation. The potential benefits of land consolidation include the following:

\section{Enabling policy environments for land consolidation}

The Ethiopian government plays a crucial role in the allocation of agricultural land. According to Ethiopia's federal constitution, which was ratified in 1995, the right to ownership of land and other natural resources is vested in "the State and in the peoples of Ethiopia". Land sale and other form hibited (Federal Democratic Republic of Ethiopia (FDRE) 1995: 14, Article 40.3). The current land law characterises the land rights of farmers as a uholding right». The law bestows on farmers the right to use rural land for purposes of agriculture and natural resource development, as well as to lease the land. Farmers may also transfer their land holding right to a family member or other lawful heirs. This also encompasses the right to generate wealth from the land and dispose of the fruits of the land (FDRE 2005: 3138 , Article 2.4). Landholding rights of farmers have no time limit (FDRE 2005: 3138-3140, Articles 7 and 9). Moreover, to ensure that farmers are aware of their land use rights and obligations under the law, the land law stipulates that holdings must be measured and registered and that holding certificates be issued explicitly stating the identity of the rights holder/s (FDRE 2005: 3138, Article 6). This has the added advantage of instilling greater confidence among farmers in their holding rights and encouraging them to undertake necessary sustainable land management practices and take part in land consolidation initiatives. The ANRS has pioneered implementation of land registration and issuance of holding certificates through a series of pilot activities.
With respect to land fragmentation and in direct reference to the benefits of land consolidation, the federal land law states that «in order to make small farm plots convenient for development, farmers are encouraged to voluntarily exchange farmands" (FDRE 2005: 3141, Article 11.3). The regul Amhara reguon's rural land administraAmhara region's rural land administration and use system encourages consolidation through voluntary exchange of land between farming households (ANRS 2007: 14, Article 10; ANRS 2017: 32, Article 20). The regulation enacted in 2007 further states that the government must provide technical services and renew provide technical services and renew (ANRS 2007:14, Article 10.2). (ANRS 2007:14, Article 10.2)

The above-mentioned technical support is, however, mainly confined to legal assistance. The regulations pertaining to land fragmentation and voluntary land consolidation lack details when it comes to the following important aspects:

the different procedures that should be followed from initiation until final implementation of VLC;

the guiding principles that should be followed and applied during implementation of VLC;

the implications of inheritance regulations for VLC and how this should be legally handled to tackle future fragmentation.

There is, therefore, a need for further refinement of regulations pertaining to land consolidation, taking into consideration the different perspectives of the farming communities. 


\section{Methodology}

To better understand the challenges of farmland fragmentation and explore the potentials of VLC, TMG Research, in close collaboration with CIAT Ethiopia, pursued the topic further and has undertaken the following research activities to explore the potential of VLC:

National-level expert consultation;

- Consultation on voluntary land consolidation with zone- and woreda-level experts in East Gojam;

- A survey of 395 households in selected kebeles of the Amhara region; and

Community consultations with farmers in Addisnagulit kebele of Gozamen woreda. The expert consultations mainly involved people from the federal Rural Land Administration and Utilization Directorate (RLAUD), experts from East Gojam zone and the Gozamen woreda Environmental Protection, the Land Use and Administration Agency (EPLUAA), research institutions and development partners. These consultations were instrumental in developing, among other things, a common understanding of primary challenges in the implementation of a VLC process. In addition, the experts provided input on the selection experts provided
of study sites.

\section{Selection of study sites}

The study sites of Addisnagulit in Gozamen woreda, East Gojam zone and Aba Jale in Woreielu woreda, and the South Wollo zone of Amhara region were purposively selected based on input from the expert consultation meetings. Specifically, the following selection criteria were used to select the two kebeles:

presence of second-level land certification with the advantage of access to geo-spatial data to establish land fragmentation and dispersion

sites with supportive local administrators;

areas representing considerable land fragmentation and exhibiting agro-ecological diversity;

- geographical representation (East Amhara (Woreielu) and West Amhara (Gozamen)).

Woreielu woreda, located in East Amhara has a rugged and mountainous topography and is prone to drought and food shortages. Gozamen woredalike many woredas in West Amhara, receives higher rainfall and is among the surplus-producing woredas of the region. In both study ing woredas of the region. In both study sites, small-scaleagriculture constitutes the primary income-generating activity The average rural household manages 0.7 hectare and 1.1 hectares of land in East and West Amhara regions respectively.

\section{Sampling}

The survey covered a total sample size of 395 households (200 and 195 households in Gozamen and Woreielu respectively). The sample size represents roughly 20 per cent of the total population in each location. Respondents were randomly location. Respondents were randomly selected, based on updated lists of farm households obtained from the respective kebele administration offices.

In order to supplement the household survey data with qualitative data, community consultations were held in Addisenagulit kebele of Gozamen woreda. These involved the Kebele Land Administration and Certification Committee (KLACC), which includes representatives from different social groups in the community, including youth and women's representatives. The consultation with the KLACC,

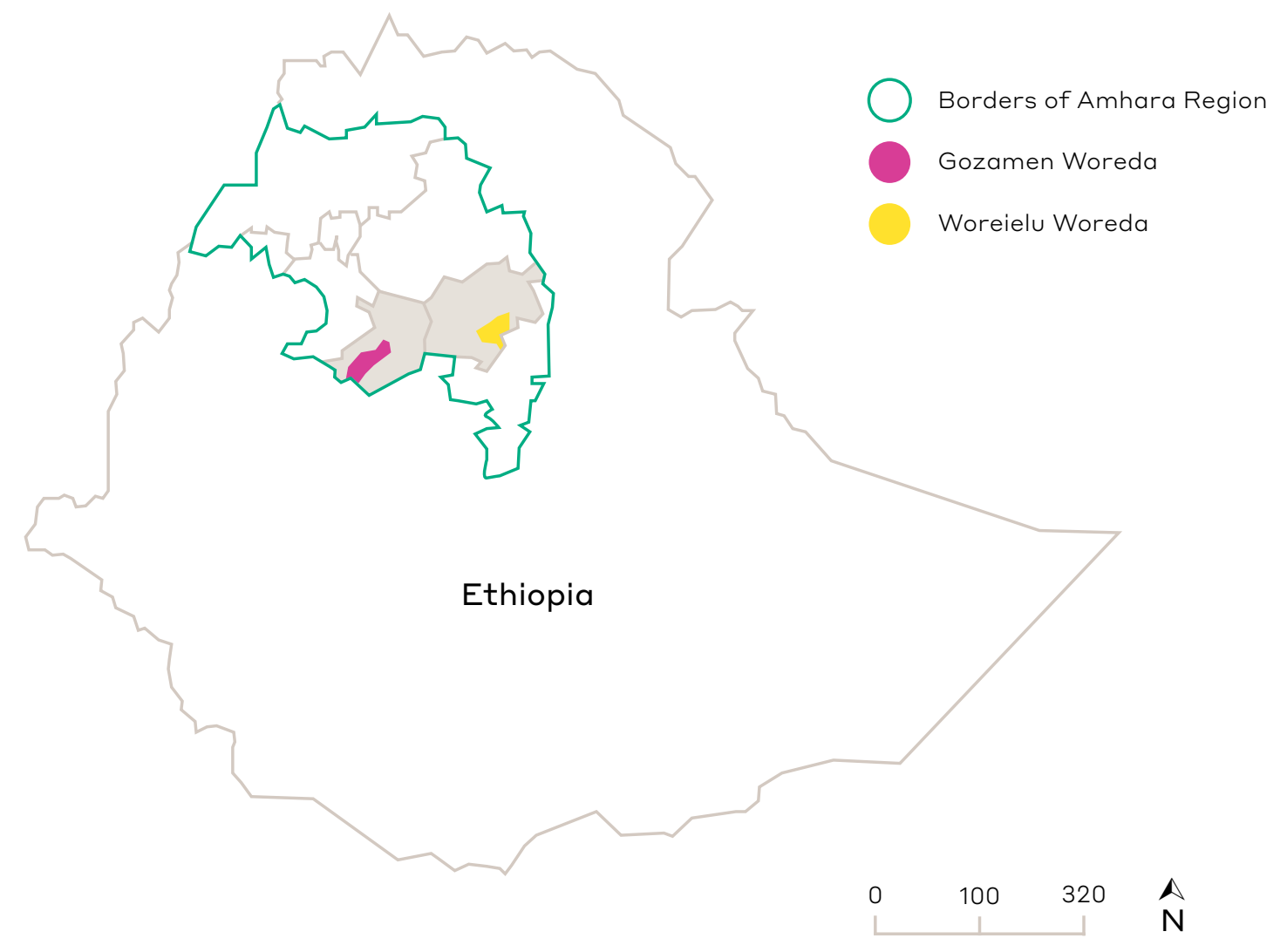

Map 1: Map of two study study sites, Gozamen and Wereilu Woreda ๑ TMG Research gGmbH 2019

as an important local-level entity dealing with land-related issues, was crucial in capturing the views of the farming community on the potential of VLC and how it should be implemented. Consultation meetings were also held with members of watershed management committees, development agents, kebele managers development agents, kebele manager and influential elders from Addi kebele. In addition to household data, the and certification geo-database was used as a secondary source of information on the size of land holdings, number of plots and the location of each plot. Maps displaying the extent of fragmentation in the kebele and showing distances in the ketwe the plots was also prepared fetween the plots was also prepare from the database and used to facilitate discussions during the community consultations.

\section{Limitations}

The community consultation meetings were restricted to Addisenagulit kebele. Due to time constraints and the regional focus of the research, consultation meetings were not conducted with farmers from Aba Jale kebele of Woreielu woreda. Considering the sensitive nature and newness of the topic, it will be important to conduct additional consultations with farmers from Woreielu woreda. Disaggregated data along criteria such as socio-economic variables, soil fertility of plots, dispersion among plots were not collected due to the survey's focus on farmers' views on the potential of VLC without the aim of analysing relationships between these variables. 


\section{The fragmentation of agricultural land and its challenges from farmers' perspectives}

More than half of the households interviewed cultivate between 5 and 15 plots (figure 1). The findings further show that the two study sites are not noticeably different in terms of size of land holding, but farmland is more fragmented in Woreielu (5.15 plots per household) than in Gozamen (3.54 plots per household).

Geo-spatial data derived from the landholding information of six selected farmers who manage six or more plots (see Table 1) provided input to the community consultations, demonstrating the distances between farm plots, a major burden of land fragmentation. Community consultations revealed that farmers in the study area plough their fields multiple times before planting crops to reduce the chance of weed germination and due to the hard soils of some fields. Table 1 below reveals the frequency of tillage performed by each farmer as part of land preparation during the previous season. This further exemplifies the burden fragmentation places on farming households.

Land fragmentation is a contested issue. Proponents argue that having plots in different areas allows farmers to better practise crop diversification, reduce the risks of crop loss and exploit different micro-climates (see, for example, Fassil 1980). However, our owr from the two kebeles show that around 80 per cent of the 370 respondents who own more than one plot experience adverse effects of land fragmentation.
In general, farmers perceive that land fragmentation puts undue pressure on them in several ways. The most commonly cited drawback at both study sites is the time taken to move from plot to plot (Figure 2). Other disadvantages linked to fragmentation include demands on labour and transport. The farmers interviewed ranked conflict related to land use, low yields due to fragmentation, and land fragmentation as an obstacle to mechanisation as less significant issues. In fact, not a single respondent in the Gozamen woreda expressed concern about mechanisation. Though the respondents did not directly identify a negative effect of fragmentation on crop yields, they mentioned that the additional time mentioned that the additional time and can negatively affect crop yields.

Participants of the community consultation in Add scattered plots run a higher isk of losing cattered plots run a higher risk of losing their harvest to wild animals, as their plots are too far away for them to regularly monitor. They also mentioned the burden on children who carry food to family members working on distant plots during planting and harvesting seasons. Several farmers also hemphized the difficulty of using even small agricultural machines, such as three-wheeled multi-purpose tractors, on discontinuous plots.

Similarly, a recent study among subsistnce farmers in three woredas of northwest Ethiopia confirmed the negative effects of land fragmentation on yields Gashaw et al 2017).
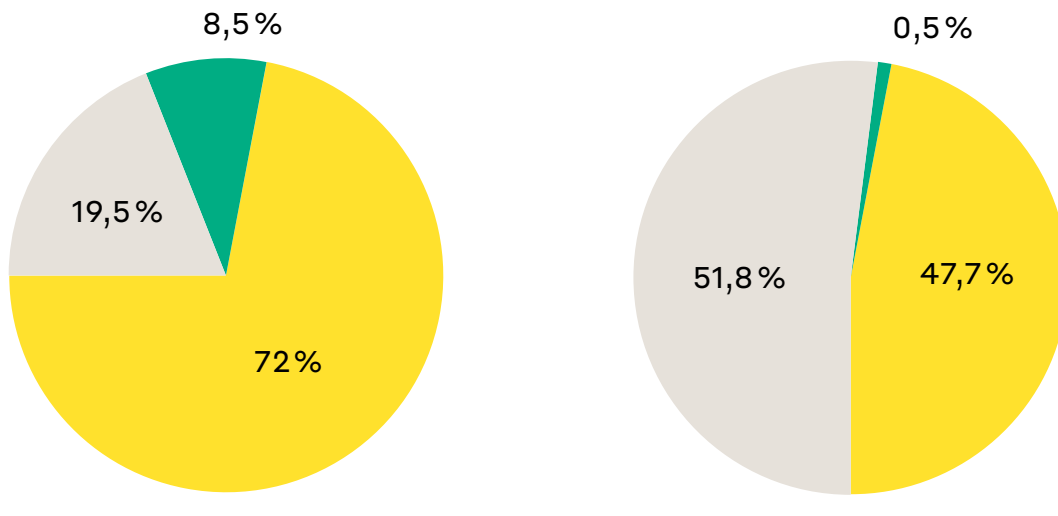

$N^{\circ}$ of Plots - Gozamen

$(n=200)$

No of Plots - Woreielu

$(n=195)$

Figure 1: Number of plots owned by respondents in Woreielu and Gozamen Woredas

\begin{tabular}{|c|c|c|c|c|c|}
\hline$N^{\circ}$ & Name & $\begin{array}{c}N^{\circ} \text { of } \\
\text { parcels }\end{array}$ & $\begin{array}{c}\text { Distance in } \mathrm{km} \text { from } \\
\text { home for one trip } \\
\text { (Direct map distance) }\end{array}$ & $\begin{array}{c}\text { Mean number } \\
\text { of trips }\end{array}$ & $\begin{array}{c}\text { Total distance in } \mathrm{km} \\
\text { from home } \\
\text { (Direct map distance) }\end{array}$ \\
\hline 1 & Farmer 1 & 10 & 29.55 & 3 & 88.65 \\
\hline 2 & Farmer 2 & 7 & 15.67 & 3 & 47.01 \\
\hline 3 & Farmer 3 & 8 & 17.03 & 3 & 51.1 \\
\hline 4 & Farmer 4 & 6 & 16.16 & 3 & 48.48 \\
\hline 5 & Farmer 5 & 11 & 34.92 & 3 & 104.75 \\
\hline 6 & Farmer 6 & 6 & 10.82 & 3 & 32.47 \\
\hline
\end{tabular}

Table 1: Number of parcels and distance from homestead of selected landholders Source Compiled from the land certification database of Addisnagulit kebele. 


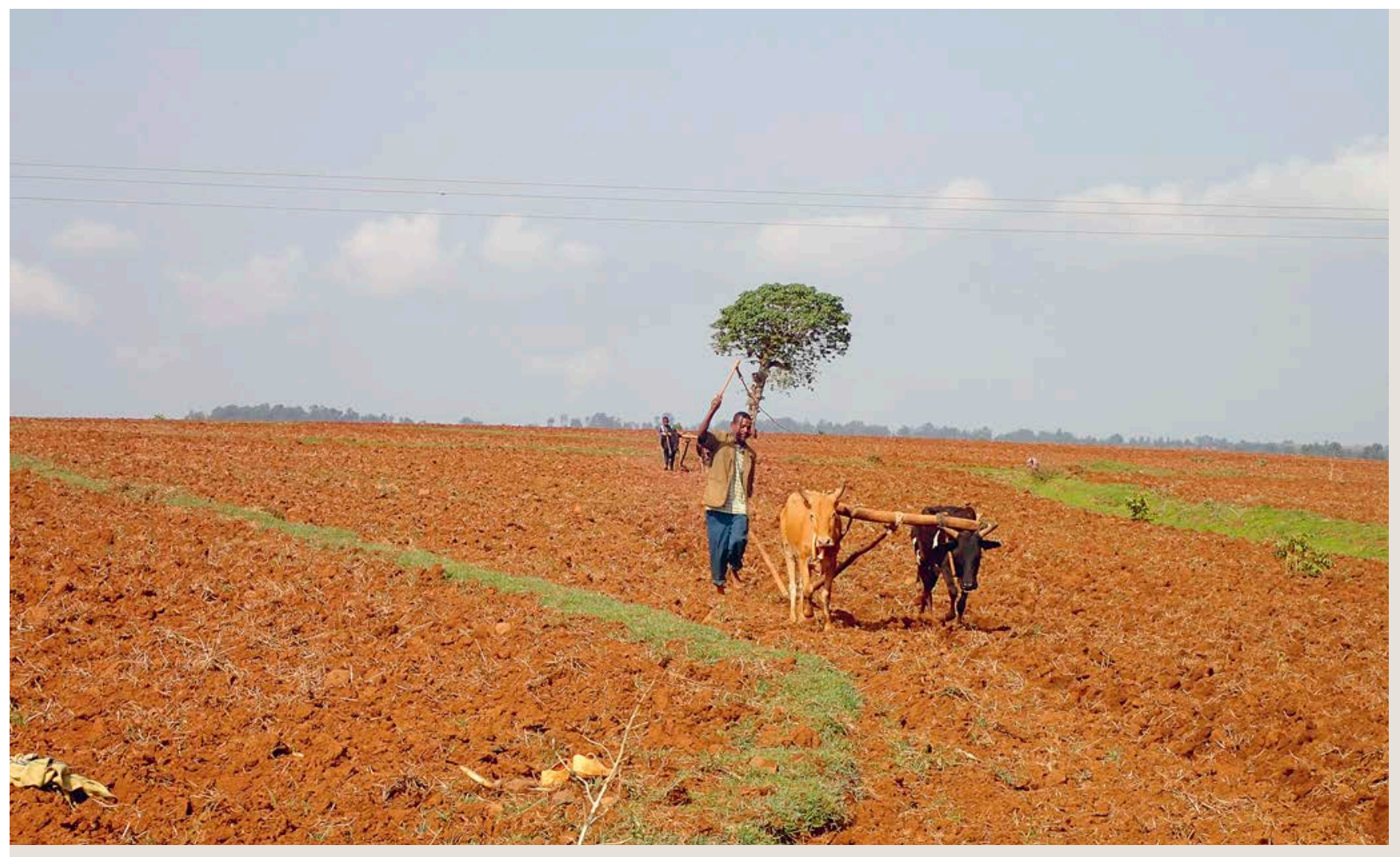

\section{Potential of voluntary land consolidation}

Photo 3: Farmers operate on discontinuous farm plots not amenable to small mechanisation o Girum Alemu/ TMG Research

Land fragmentation and the cultivation of discontinuous fields is said to hinder the expansion of improved mechanical technologies and the efficient use of irrigation (Demetriou 2014). In fact, the majority of interviewed farmers during the household survey ( 81 per cent) expect that land consolidation can alleviate the challenges that they are currently experiencing due to fragmented holdings. In terms of the expected benefits of land consolidation, efficiency gains in farm management (81 per cent on average) ranks highest. This mirrors what the farmers identified as the main challenge with land fragmentation; the time lost travelling to multiple and distant fields. Mechanisation and yield improvements were weakly linked to land consolidation (below 10 per cent on average), reflecting farmers' responses with regards to challenges of land fragmentation. By contrast, efficiency gains in monitoring farm activities were ranked lowest in terms of the potential benefits of land consolidations; whereas difficulties in monitoring was relatively prominently mentioned (second most important challenge for farmers in Gozamen woreda) in terms of challenges associated with land fragmentation.

Similar positive assessments of land consolidation were observed during the community consultation. In particular farmers mentioned the advantages of having farm plots con area to give due attention to soll ferti area to give due attention to soil fertility improvement measures and combine it with livestock fattening. They further mentioned that the more fertile plots are those within closest reach of the farmers, allowing them to more easily monitor and apply soil fertility improvement technologies such as improved compost. Farmers also expect that land consolidation would enable them to put moreland tion would enable them to put more land under irrigation (including opportunities to intensify use of underground water for supplementary irrigation) 


\section{Perceived benefits of land consolidation}

Easy to manage

Easy input transport

\section{Saves labor}

Reduces cost

Improved yield due to timely

ilitates mechanisation

Efficiency of monitoring

farm activity

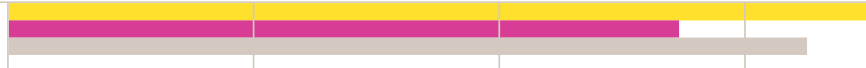

\section{\begin{tabular}{|l}
\hline \\
\hline \\
\hline \\
\hline \\
\hline
\end{tabular}}

$$
0
$$

$25 \%$

$50 \%$

$75 \%$

Woreielu

Gozamen

Total

Figure 3: Perceived benefits of land consolidation ( $N=319$, multiple answers possible)

\section{Circumstances/incentives for Consolidation}

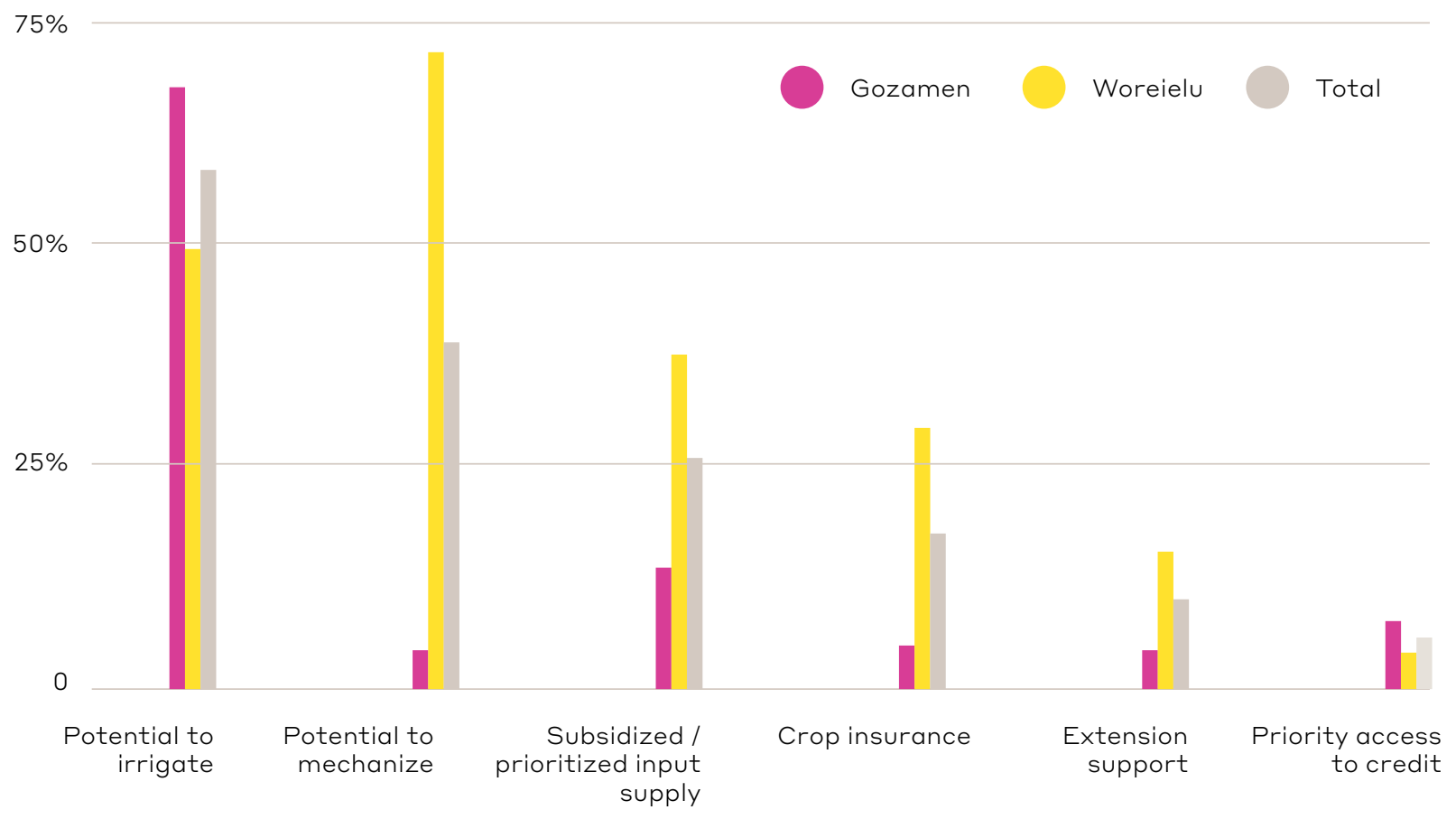

Managing risks associated with land consolidation

While more than 80 per cent of interviewed households see value - in principle - in farmland consolidation, farmers are also aware of risks associated with land consolidation. Sometimes land fragmentation is considered as a risk-spreading strategy by farmers, minimizing the risk of harvest loss by planting crops in different locations. During community consultations, farmers raised concerns about the risks associated with concentration of farmland in one place, such as infestation by armyworm and destruction by hail or floods. In the light of these perceived risks, the availability of short maturing crops and crop insurof short maturing crops and crop insurincentives for participation in voluntary incentives for participation in voluntary land consolidation processes. In addition, participants in the community consultations argued that it is important to conas farm assets, such as cash crops, in developing valuation criteria. They also recommended considering context-specific and locally acceptable valuation indicators to minimise the risk of future conflicts around land consolidation.

Conditions and incentives for voluntary land consolidations

Consolidation, as one instrument to deal with farmland fragmentation, can be facilitated by providing support to those who are willing to participate in it. In this regard, the respondents were asked which conditions should be in place to incentivise VLC. Farmers in Woreielu woreda have a strong preference for mechanisation (72 per cent) and improved irrigation (50 per cent) as incentives for VLC (figure 4), whereas farmers in Gozamen woreda (68 per cent) mostly see irrigation as an important incentive. Mechanisation, along with extension support, is ranked lowest among farmers in Gozamen. One important policy lesson that can be drawn from this is that there is a conducive local environment through which land consolidation can be pushed further in a voluntary but systematic manner.

In addition to incentives that would motivate farmers to participate in VLC, we also enquired about farmers' preferred locations for land consolidation. A significant majority of the farmers from Woreielu woreda (87.3 per cent) preferred a plot near to their house (figure 5). Proximity to road infrastructure and irrigation facilities was ranked second and third respectively. In Gozamen, on and third respectively in Gozamen, on the other hand, proxinity to homesteads (32 per cent) was ranked second, after proximity to points of irrigation (49 per cent).

\section{Prior experience of swapping}

farmland

As mentioned earlier, there have been few land consolidation projects from which subsistence farmers could draw lessons. This means that farmers can only draw This means that farmers can only draw on the experiences of other farmers who swapped their plots. This lack of comprehensive information on land consolidation was also reflected in the survey data: 68 per cent of the farmers interviewed do not have experience of swapping land in order to concentrate their holding in one place. However, a few farmers still pursued spontaneous land consolidation to minimize the effects of fragmentation. Of the 124 households who had experience in plot exchange, nearly half were motivated by the prospect of better access to irrigable land (Figure 6). Other important reasons for swapping farmland include facilitation of farm operations (18 per cent), and shorter distances to residence (17 per cent) and to road and town infrastructure (16 per cent). 


\section{The need to accommodate}

\section{farmers' interests and concerns}

In general, the results from the household survey and community consultations revealed that land consolidation is much needed to address the various challenges of farmland fragmentation and dispersion. Some farmers took the initiative to serve the immediate need of the house holds. However, a land consolidation process based on individual farmer initiatives has limited scope and impact and is likely to take longer. Thus, the responsible land administration and utilisation offices closer to the community need to facilitate and support the process systematically. During community consultations, farmers also suggested ways of addressing concerns over variations in soil fertility. Though variations in soil fertility are physically evident, the deci- sion to exchange plots with different fertility status is determined by housefertility status is determined by household's preference. For example, some farmers did not see differences in soli fertility as a major barrier to swapping land and consolidating holdings, as long as all of the plots were concentrated in one place. However, other farmers saw the swapping of plots between areas of similar soil fertility as a practical entry point for land consolidation. To address point for land consolidation. To address this and other potential challenges and tion, farmers suggested creating locally agreed land consolidation zones based on soil fertility status, presence of irrigation infrastructure and predominant crops. In addition, farmers emphasised the need for repeated events to raise awareness and clarify issues through combined use of local and scientific knowledge.

\section{Preferred Locations for land consolidation}

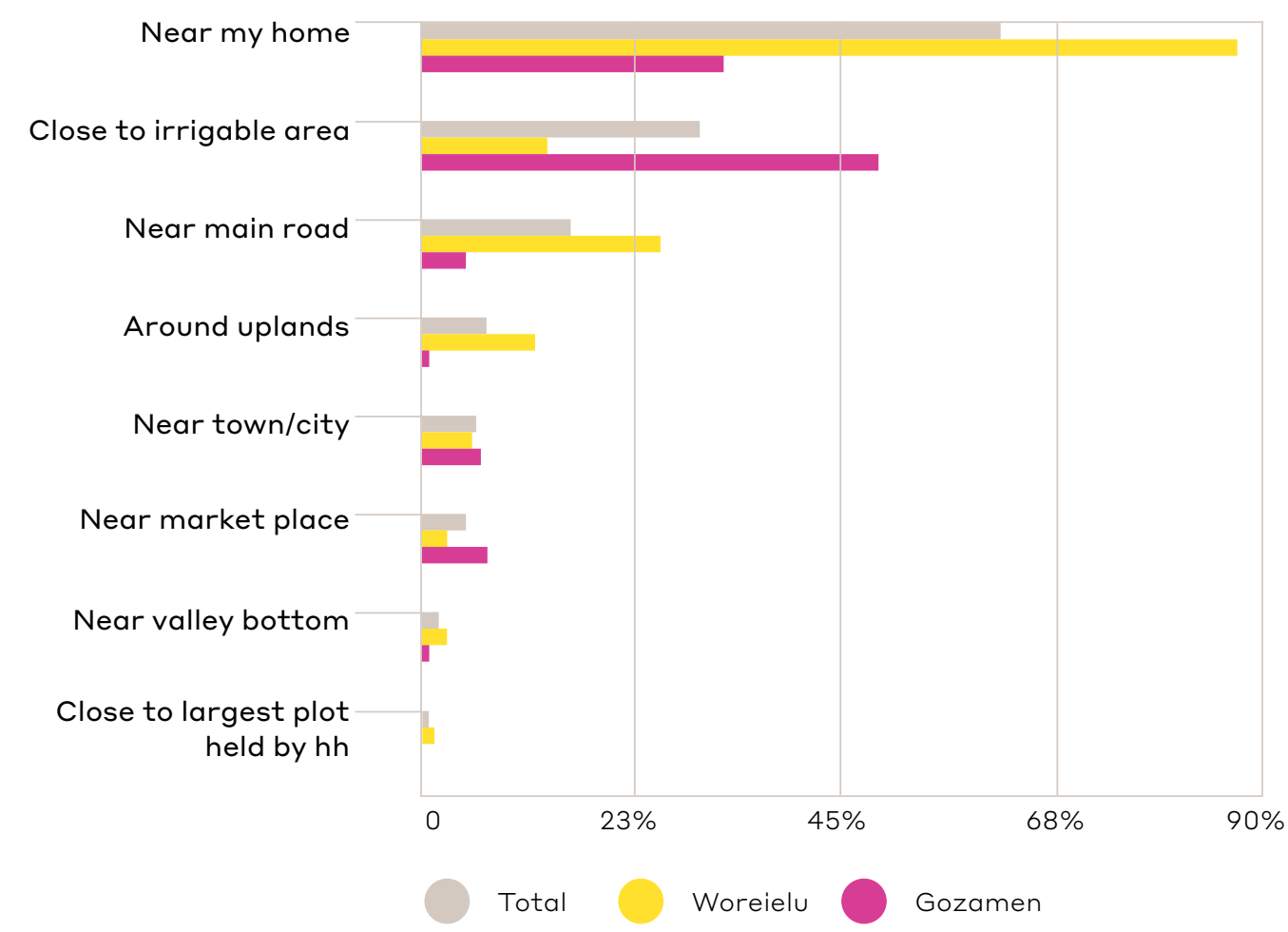

Figure 5: Farmers' preferred locations for land consolidation ( $N=377$, multiple answers possible)

\section{Reasons for Plot Exchange}

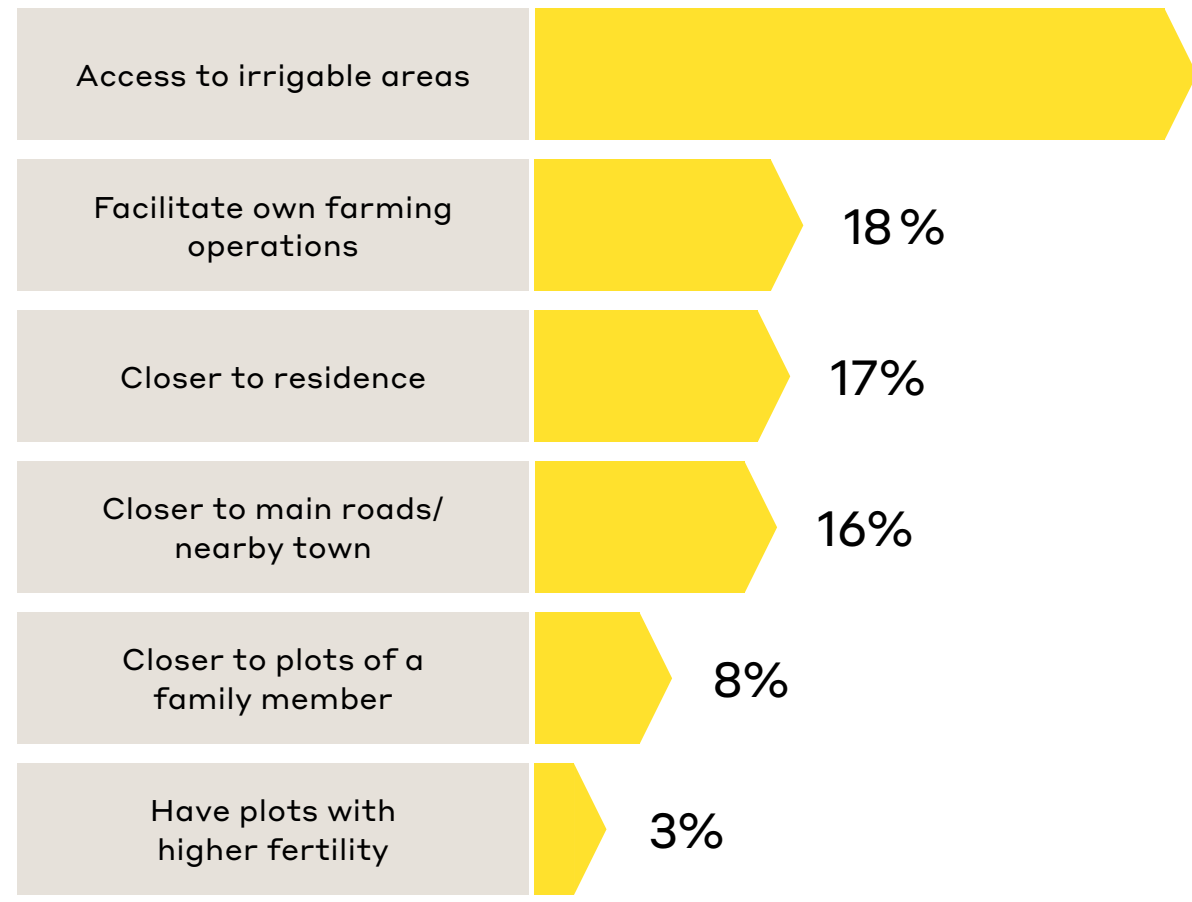




\section{Way forward: Continued consultations and stakeholder engagement}

Voluntary land consolidation can be a policy instrument to address the challenges of subsistence agriculture in Ethiopia. We found a general positive recognition by farmers of the potential of land consolidation. Among other things, land consolidation can lead to improved agricultural productivity and management of natural resources. It can also improve rural development and enhance land administration systems. For example, it is easier and less costly to monitor and document farming practices on consolidated holdings than on scattered plots. However, despite its potential, there have been few policy discussions or pilot projects on VLC.

Several conditions should be in place before a land consolidation project is initiated. First, stakeholders should be willing to participate actively in the decision-making process. Second, the process should be demand-driven and a project site must be identified where farmers and local authorities are interested in land consolidation $c$ consolidation. One important policy lesson that can be drawn from this is that, with adequate incentives in place, it is possible to promote land consolidation in a voluntary yet systematic manner. To achieve this, the different departments under the Ministry of Agriculture need to identify the pull factors that may attract famers to land consolidation and respond accordingly.
Further research needs to be conducted to carefully examine the role land fragmentation plays in the farming practices of smallholders. Such an understanding is crucial for identifying the contexts where land consolidation can be an instrument for reducing land fragmentation. Further research needs to be conducted to better understand the underlying factors behind farmers' attitudes to VLC and outline keyvariat a that comes of land consolidation

The successful initiation and implementation of $V L C$ requires concerted efforts from different stakeholders to move the process forward. In this regard, genuine engagement and dialogue with farmers representing different segments of the community, rural land administration experts, policy makers and international development partners is essential to successfully pilot voluntary land consolidacessfuly pilot voluntary land consolidation and further develop implementation modalities. The inputs from project implementation can, in turn, guide policy dialogues and refinement of regulations related to land consolidation.
References

ANRS (Amhara National Regional State), 2007. «The Amhara National Regional State Rural Land Administration and Use System Implementation, Council of

Council of the Amhara National Regional State in the Federal Democratic Republic of Ethiopia, 2017. 2017. «The Revised Rural Land Administration and Use Determination Addis Ababa, Ethiopia.

ATA (Agricultural Transformation Agency), 2017. «Agricultural Commercialization Cluster Initiative: Design, Implementation Approach, Focus Value Cha

CSA (Central Statistical Agency), 2015. Agricultural Sample Survey 2014/2015: Report on and Utilization (Private Peasant Holdings, Meher Season). CSA, Addis Ababa, Ethiopia.

Daniel A., Deininger, K., and Loraine R., 2015. «Costs and Benefits of Land Fragmentation: Evidence from Rwanda' Policy Research Working Paper 7290. Washington DC: World Bank Group, Development Research Group, Agriculture and Rural Development Team

Enyew A., Yihenew G., Abate T., Solomon A., and Abiye A., 2014. «lmpact of land certification on sustainable land resource management in the amhara region, Ethiopia," Tech. Rep., Dry lands Coordination Group, Miljøhuset G9, Norway, Ethiopia, April 2014, DCG Report No. 75

FDRE - Federal Democratic Republic of Ethiopia, 1995. The Constitution of the Federa Democratic Republic of Ethiopia. Negarit Gazeta, 1st Year No.1, Addis Ababa Ethiopia.

. Proclamation No. 456/2005, Addis Ababa, Ethiopia.

Dessalegn R, 1994, «Land Policy in Ethiopia at the Crossroads». Paper for the Workshop on 'Land Tenure and Land Policy, Addis Ababa: Addis Ababa University.

EEA (Ethiopian Economic Association). 2002. A Research Report on Land Tenure and Agricultural Development in Ethiopia. Addis Ababa, Ethiopia: Ethiopian Economics Association

Fantu N., Guush B., Minten, B., and Alemayehu S., 2015. Agricultural Growth in Ethiopia (2004-2014): Evidence and Drivers. Addis Ababa: IFPRI-Ethiopia Strategy Support Programme, Working Paper 81 .

Fassil G., 1980. «Land Fragmentation: A Problem of Land Distribution Observed in Some. pp. 1-12

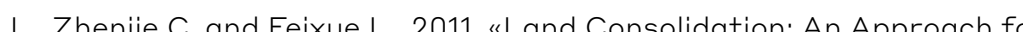
Sustainable Development in Rural Chinam. AMBIO 40, pp. 93 - 95.

Ho D. and McPherson M., 2010. «Policy for Socioeconomic Development in Vietnam». Fulmocratic Governance

Shimelles T., Islam Z., and Parviainen T., 2009. «Effects of Land Tenure and Property Rights on Agricultural Productivity in Ethiopia, Namibia and Bangladesh, "in Discussion Panen

Netics of Property Units in Ethiopia, the Case of Two Pllot Projects in Amhara National Regional State». Nordic Journal of Surveying and Real Estate Research 6:2, pp.7-24 
TMG Working Paper

May 2019

TMG - Think Tank for Sustainability

TMG Research gGmbH

EUREF-Campus 6-9

10829 Berlin, GERMANY

Telephone: (+49) 3092107407 00

Email: info@tmg-thinktank.com

Website: www.tmg-thinktank.com

This publication is made possible with the financial support by the German Federal Ministry for Economic Cooperation and Development (BMZ). 